\title{
(Austin Publishing Group
}

\section{Clinical Image}

\section{Focal Hepatic Hot Spot Sign}

\author{
Mohamed DA*, Retal H, Onka B, Latib R and \\ Omor Y \\ National Institute of Oncologic, University Hospital \\ Center Ibn Sina, Rabat, Morocco \\ *Corresponding author: Daoud Ali Mohamed, \\ Radiology Department, University Hospital Center Ibn \\ Sina, Rabat, Morocco
}

Received: June 04, 2021; Accepted: July 06, 2021; Published: July 13, 2021

\section{Clinical Image}

A 55-year-old woman followed for right plantar melanoma with secondary localization (cerebral, thoracic and abdominal) treated with chemotherapy. Three months later, the CT scan showed an increase of the mediastinal mass compressing the mediastinal vascular structures, in particular the superior vena cava (Figure 1). $\mathrm{CT}$ of the abdomen revealed an intense wedge-shaped homogeneous enhancement area in the quadrate lobe of the liver (Figure 2).

\section{Discussion}

The focal hepatic hot spot sign was first described in 1983 by Ishikawa. The sign can be observed on technetium $99 \mathrm{~m}$ (99mTc) Sulphur colloid scans or on contrast, material enhanced CT scans [1]. This abnormal enhancement is due to portosystemic venous shunting between the SVC and portal vein. The hot spot is created by areas of focally increased blood flow that result from this shunting [2].

This sign has been reported in Budd-Chiari syndrome, the causes of SVC syndrome (neoplasms of the thorax as lung carcinoma and lymphoma, Vasculo-Behcet's disease, fibrosing mediastinitis, and luetic aneurysm) [3].

There are other conditions which can result in increased uptake such as hemangioma, hepatocellular carcinoma, focal nodular hyperplasia, which if they occur in regions adjacent to the falciform ligament in segment IV can mimic the focal hepatic hot spot sign.

\section{References}

1. Dickson AM. The focal hepatic hot spot sign. Radiology. 2005; 237: 647-648

2. Hoang VT, Vo NQ, Trinh CT, et al. The focal hepatic hot spot sign with lung cancer in computed tomography. Respirol Case Rep. 2020; 8: e00671.

3. Phoophiboon V, Tantiprawan $\mathrm{J}$, Vanakiatkul $\mathrm{H}$ and Wongkarnjana $\mathrm{A}$. Systemic to pulmonary venous shunt and the focal hepatic hot spot sign from SVC obstruction in Behcet's disease. BMJ Case Rep. 2020; 13: e234017.

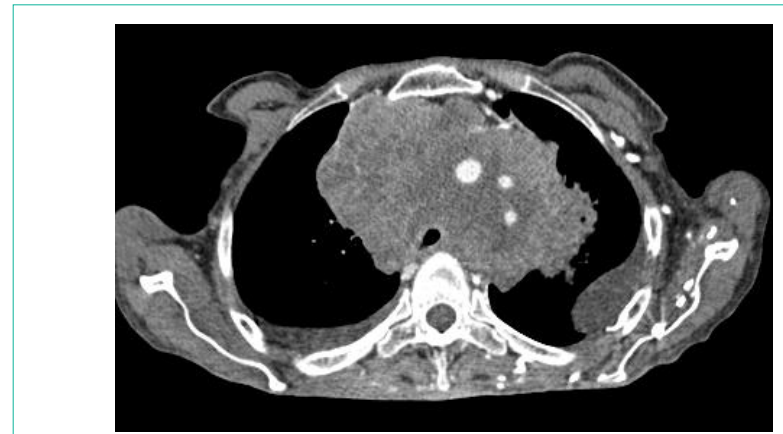

Figure 1: Axial contrast enhanced CT of the chest showing a mediastinal mass (metastasis of a melanoma) compressing the vascular structures with obstruction of the superior vena cava.

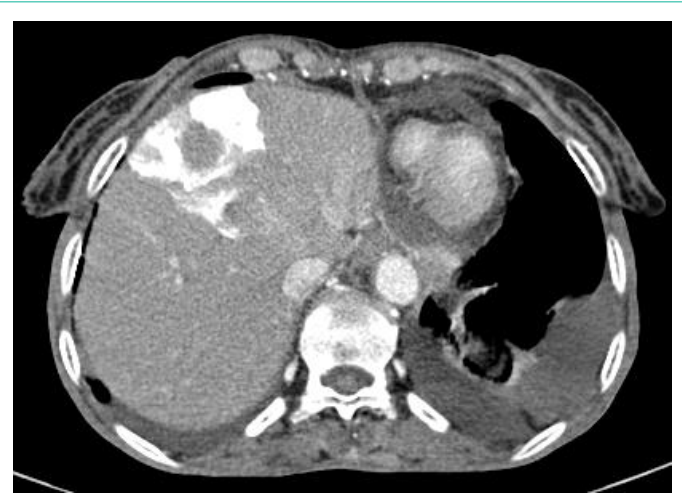

Figure 2: Axial contrast enhanced CT of the abdomen showing an intense wedge-shaped enhancement area in the quadrate lobe of the liver in late arterial phase : sign of the focal hepatic hot spot sign. 